\title{
BMJ Open Recall of physical activity advice was associated with higher levels of physical activity in colorectal cancer patients
}

\author{
A Fisher, K Williams, R Beeken, J Wardle
}

To cite: Fisher A, Williams $\mathrm{K}$, Beeken $\mathrm{R}$, et al. Recall of physical activity advice was associated with higher levels of physical activity in colorectal cancer patients . BMJ Open 2015;5:e006853. doi:10.1136/bmjopen-2014006853

- Prepublication history for this paper is available online. To view these files please visit the journal online (http://dx.doi.org/10.1136/ bmjopen-2014-006853).

Received 7 October 2014 Revised 13 March 2015 Accepted 18 March 2015

CrossMark

Department of Epidemiology and Public Health, University College London, London, UK

Correspondence to

Dr A Fisher;

abigail.fisher@ucl.ac.uk

\section{ABSTRACT}

Objectives: The present study tested the hypothesis that recall of receiving physical activity $(\mathrm{PA})$ advice would be associated with higher levels of PA in patients with a diagnosis of colorectal cancer (CRC).

Setting: Colorectal cancer patients who were diagnosed in 2010 or 2011, and had been treated in the English National Health Service (NHS).

Participants: 17753 respondents completed at least one section of the survey relevant to the current study and after exclusion of 171 with dementia (since results relied on recall), 15254 had complete data for the current study. $60 \%$ were male, $67 \%$ were $>65$ years and $96 \%$ were from a white ethnic group.

Primary and secondary outcome measures: Patients completed the 'Living with and Beyond Colorectal Cancer' Patient-Reported Outcome Measures (PROMS) survey in 2013. The survey included questions on receiving exercise advice/information ('PA advice'), and the frequency of currently doing at least 30 min of brisk PA per day ('PA level': $0,1-4$ or 5-7 days, within the past week; with the top category meeting UK guidelines).

Results: A third of respondents (31\%) recalled receiving $P A$ advice. Independent of demographics and treatment, patients who recalled having PA advice were more likely to be currently doing some brisk PA $(51 \%$ in the advice group vs $42 \%$ in the no advice group; $O R$ $1.74,95 \% \mathrm{Cl} 1.60$ to $1.90 ; p<0.001$ ), and more likely to be meeting PA guidelines ( $25 \%$ vs $20 \%$; OR 1.70 , Cl 1.54 to 1.88; $p<0.001$ ).

Conclusions: Recalling being given PA advice after a diagnosis of CRC was associated with higher levels of PA. However, less than a third of patients recalled receiving advice. Future research should examine the context in which advice is given and randomised trials are required. However, encouraging clinicians working with patients with CRC to give brief PA advice is warranted and may help improve outcomes for CRC survivors.

\section{INTRODUCTION}

There is now a solid body of evidence that a physically active lifestyle is associated with

\section{Strengths and limitations of this study}

- This is the first very large population-based study to explore whether physical activity advice is given to colorectal cancer patients; proportions who recalled receiving advice were low.

- Physical activity advice during the cancer care pathway was associated with higher levels of physical activity.

- The findings of this study provide strong impetus to clinicians working with colorectal cancer to recommend physical activity, a practice which does not yet appear to be routine in the UK.

- This study is limited in relying on patient report of physical activity levels and recall of whether they were given advice. However, the PatientReported Outcome Measures data are designed to collect data on patient experience on a large scale.

- Data on the context of the advice were not available and this should be a focus of future research.

better long-term outcomes following a diagnosis of colorectal cancer (CRC).${ }^{1-3}$ A meta-analysis of 7 prospective cohort studies demonstrated that higher postdiagnosis physical activity (PA) was associated with lower CRC-specific and all-cause mortality. ${ }^{1}$ A report from the Cancer Prevention Study-II (CPS-II) Nutrition Cohort showed associations with all-cause mortality for both postdiagnosis PA and sedentary time. ${ }^{2}$ PA has also been associated with better quality of life and lower levels of cancer-related fatigue. ${ }^{3}$

CRC survivors typically have lower levels of PA than the general population ${ }^{4}$ and data from the English Longitudinal Study of Ageing showed a faster decline in activity over time in participants who received a cancer diagnosis than the rest of the cohort. ${ }^{5}$ Intervention within the clinical care pathway to promote PA could help CRC survivors achieve the health gains associated with an active lifestyle. 
Clinicians dealing with patients with cancer are in a good position to offer activity advice, and they are the patients' preferred source of information. ${ }^{6}$ Patients also specifically express a wish for those involved in their care to initiate discussion about PA during consultation. ${ }^{7}$ However, evidence to date indicates that most patients with cancer are not receiving PA advice. In a US survey, conducted in 2008, 38\% of oncologists and surgeons said they did not enquire about patients' activity levels. ${ }^{8}$ A similar study in the UK found that $56 \%$ of healthcare professionals did not discuss PA with their patients with breast cancer ${ }^{9}$ and a more recent survey suggested little improvement in these figures. ${ }^{10}$ These findings are broadly consistent with reports from cancer survivors themselves, with only a third of patients with breast or prostate cancer reporting being given any PA advice. ${ }^{11}$ Primary care physicians are another source of lifestyle advice, but although US data indicate some increase in provision of PA advice for patients with cancer in primary care $(25 \%$ in $2000,36 \%$ in 2010$)$, the rates are still too low. ${ }^{12}$

Brief PA advice in primary care has been shown to increase PA in sedentary adults ${ }^{13}$ and a review concluded that it was an effective intervention, at least in the short-term. ${ }^{14}$ Studies in cancer survivors also indicate that clinicians discussing PA with their patients might have a positive effect on activity levels. A survey of 311 cancer survivors (38 with CRC), found that oncologistinitiated discussion of PA was associated with higher activity levels during treatment ${ }^{7}$ and an exploratory study in 24 breast cancer survivors suggested that a clinician recommendation was an important factor in exercise adherence. ${ }^{15}$ In one of the few trials of brief advice in cancer survivors, a simple PA recommendation doubled the percentage of breast cancer survivors meeting national exercise guidelines, with stronger effects among those who correctly recalled the advice, although the follow-up interval in this study was only 5 weeks. ${ }^{16}$

The current study used data collected from a very large sample of patients with CRC to test the hypothesis that recalling being given PA advice would be related to higher levels of physical activity.

\section{MATERIALS AND METHODS}

\section{Participants and measures}

Data were from the Living with and Beyond Colorectal Cancer survey commissioned by the UK Department of Health in 2013, as part of a programme of work designed to ensure that the needs of patients with colorectal cancer in the UK are met across a range of health, psychosocial and lifestyle domains through the recording of patient-reported outcomes (PROMS). ${ }^{17}$ The questionnaire was mailed by the National Cancer Registration Service (NCRS), in 2013, to a sample of 34467 adult patients with a recorded diagnosis of CRC in 2010 or 2011, who were treated in the English National Health Service, and who were $>16$ years and were 12-36 months postdiagnosis. Content and face validity for the PROMS survey were identified through expert reviews and consultations with patients, experts and charity advisory groups. ${ }^{18}$ For the current study, a formal request was made by the study authors to the NCRS for health and lifestyle data for the secondary analyses.

The questionnaire section 'Overall Support and Care' included the question 'Did you receive any advice or information on physical activity and exercise ("physical activity advice')?' This was within a longer list of cancer-relevant domains of information, including physical and psychological aspects of living with cancer, finance, employment, family and support services.

Current PA was assessed by asking: 'In the past week how many days have you done 30 min or more of brisk physical activity (This may include sport, exercise or brisk walking or cycling for recreation or to get to and from places, but should not include housework that or physical activity that is part of your job)?' Responses were categorised as 'none' (0 days), 'some' (1-4 days) or 'meeting guidelines' ( $5-7$ days), broadly in line with the UK Government recommendations for the general population ${ }^{19}$ and the American College of Sports Medicine recommendations that cancer survivors should participate in at least $150 \mathrm{~min}$ per week of at least moderate activity. ${ }^{20}$ There were also data on sex and age at diagnosis (obtained from registry data), and ethnicity (reported by patients). Index of Multiple Deprivation (IMD) scores were calculated for the home postcode (1-5 from least to most deprived). ${ }^{21}$ IMD is an area level measure derived from a composite of 38 indicators across seven domains of deprivation, including income, employment, health, education, housing and services, living environment and crime. $^{21}$

There were a variety of treatment questions, but for these analyses we included: 'How has your CRC responded to treatment?' ('fully responded I am in remission', 'has been treated but is still present', 'has not been treated', 'has come back after initial treatment', 'not certain what is happening'). Length of time since treatment was also reported. Long-term health conditions (LTCs) were assessed with 'Do you have a long-standing health condition other than cancer?' ('yes', 'no', 'can't say'). As the focus of this analysis was on recall of receiving PA advice, patients reporting a diagnosis of dementia were excluded. The full survey is available at cancerproms.ncr.nhs.uk. In accordance with UCL Ethics Committee guidance, additional ethical approval was not required for secondary analyses of anonymous health surveillance survey data.

\section{ANALYSES}

Where $>75 \%$ of respondents fell into a single response category, predictor variables were dichotomised for analyses. However, full descriptive data, including the proportion of missing values, are presented in the results. Ethnic groups were categorised as 'white' versus 'all 
other'. Since health and treatment variables were secondary to the main research question, missing data were recoded as 'unknown' for analyses to include as many respondents as possible. Response to treatment was categorised as 'in remission' versus 'all other'. Time since treatment was coded as 'Still having treatment', ' $<1$ year' post-treatment, ' $\geq 1$ year', or 'unknown'. Presence of an LTC was recorded as 'yes', 'no', or 'unknown'.

Descriptive statistics and percentages in each category were calculated. Two types of logistic regression were carried out. First, to assess factors associated with whether PA advice was given, a binary logistic regression with 'advice' or 'no advice' as the outcome was carried out. Second, to assess whether advice related to activity levels, a multinomial logistic regression model with PA level (none/some/meeting activity guidelines) as the outcome was carried out. In each case, simple associations and then models adjusted for potential confounders were presented. Analyses were carried out in SPSS V.18. Given the large sample size, significance was set at $\mathrm{p}<0.01$.

\section{RESULTS}

Of the 34467 questionnaires mailed out by NCRS, $21802(63.3 \%)$ were returned at least partially completed and further information on this sample are provided in a recent paper by Downing et al. ${ }^{22}$ Regarding the data granted from NCRS for the current study, 17753 patients had responded to at least 1 question in the relevant parts of the survey. Compared to nonresponders, these participants were less likely to be from deprived areas and fewer were from the youngest ( $<55$ years) and oldest ( $>85$ years) age categories $(\mathrm{p}<0.001)$. After exclusion of $171(1.1 \%)$ patients with dementia, complete data on the PA questions and demographics were available for 15254 patients; this constituted the study sample. Characteristics of the 17753 patients who completed at least 1 question in the relevant parts of the survey and the study sample were very similar, and are shown in table 1.

$67 \%$ were $>65$ years old, $60 \%$ were male, and $96 \%$ identified themselves as 'white'. Most patients reported that their cancer had fully responded to treatment and they were in remission (79\%), with smaller numbers reporting that the cancer was still present $(5 \%)$, had not been treated $(1 \%)$, had come back after initial treatment $(3 \%)$ or that they were not certain $(9 \%)$; however, $4 \%$ did not respond to this question. The majority $(>80 \%)$ of patients were at least 1 year since treatment. Forty-seven per cent reported a long-standing health condition other than cancer, $3 \%$ 'couldn't say' and $11 \%$ did not respond. Forty-five per cent of patients reported doing at least some brisk activity and $22 \%$ met the guidelines for PA, but 33\% reported doing none.

Overall, $31 \%$ of respondents recalled having received any PA advice. The proportion receiving PA advice by demographics, treatment and LTCs is shown in table 2.
Men were more likely than women to recall being given advice (35 vs 25\%; OR 1.66, $95 \%$ CI 1.55 to 1.79 ; $\mathrm{p}<0.001)$. Younger patients were more likely than older patients to recall advice $(37 \%$ in the $<55$-year-olds vs $20 \%$ in >85-year-olds (OR 2.41, CI 1.95 to 2.90; $\mathrm{p}<0.001)$. Patients from higher SES groups were more likely to recall advice than those from lower SES groups (comparing highest to lowest SES, 32\% vs 28\%; OR 1.25, CI 1.10 to $1.43 ; \mathrm{p}<0.001$ ), but there was no significant association with ethnicity. Patients in remission were more likely to recall being given PA advice ( $32 \%$ vs $27 \%$; OR 1.23 , CI 1.12 to $1.30 ; \mathrm{p}<0.001)$, and in the fully adjusted model, patients with a LTC were statistically more likely to recall advice, but the magnitude of this difference was extremely small $(32 \%$ vs $31 \%$; $\mathrm{p}<0.001)$ and unlikely to be clinically meaningful. Time since treatment was not associated with advice in the adjusted model.

Consistent with our hypothesis, recalling being given PA advice was associated with higher levels of current activity. Fifty-one per cent of patients who had been given advice were doing at least some activity, with $25 \%$ meeting the guidelines, compared with $42 \%$ and $20 \%$, respectively, in the 'no advice' group (see table 3 and figure 1). Compared with the 'no advice' group, the odds of doing some activity were 1.88 (CI 1.74 to 2.05; $\mathrm{p}<0.001)$ and the odds of meeting guidelines were 1.90 , (CI 1.75 to $2.09 ; \mathrm{p}<0.001$ ) among those who were given advice.

There were associations between demographic variables and activity levels (men, younger patients and those from higher SES backgrounds were more active; table 2), but associations between PA advice and activity levels remained significant after controlling for these and the adjusted odds were similar to the unadjusted values (OR 1.74, CI 1.60 to $1.90, \mathrm{p}<0.001$ for doing some activity; OR 1.70 , CI 1.54 to $1.88, \mathrm{p}<0.001$ for meeting guidelines).

Similarly, although some health and treatment factors were related to activity levels (table 4), the association between PA advice and current activity levels remained after adjustment for treatment and presence of any LTC.

\section{DISCUSSION}

To the best of our knowledge, this was the largest population-based study to explore the extent to which patients with cancer are given PA advice, and the only one to examine associations between recall of PA advice and activity levels in patients with CRC. Consistent with findings from other studies, ${ }^{8-11}$ a relatively small proportion recalled being given PA advice. In support of our hypothesis, recall of advice was associated with higher activity levels, even after adjustment for sociodemographics and treatment factors.

The finding that being given advice related to later activity levels in patients with CRC is supported by evidence from a small RCT in breast cancer survivors, 
Table 1 Full demographics and treatment variables from responders and study sample

\begin{tabular}{|c|c|c|c|c|}
\hline \multirow[b]{2}{*}{ Demographics } & \multicolumn{2}{|c|}{$\begin{array}{l}\text { Responders } \\
n=17753\end{array}$} & \multicolumn{2}{|c|}{$\begin{array}{l}\text { Study sample } \\
n=15254\end{array}$} \\
\hline & $\mathrm{n}$ & Per cent & $\mathrm{n}$ & Per cent \\
\hline \multicolumn{5}{|l|}{ Sex } \\
\hline Female & 7295 & 41.1 & 6091 & 39.9 \\
\hline Male & 10458 & 58.9 & 9163 & 60.1 \\
\hline \multicolumn{5}{|l|}{ Age } \\
\hline$>85$ & 969 & 5.5 & 777 & 5.1 \\
\hline$\overline{75}-84$ & 4508 & 25.4 & 3797 & 24.9 \\
\hline $65-74$ & 6195 & 34.9 & 5680 & 37.2 \\
\hline $55-64$ & 3712 & 20.9 & 3677 & 24.1 \\
\hline$<55$ & 1585 & 8.9 & 1323 & 8.7 \\
\hline Missing & 784 & 4.4 & - & - \\
\hline \multicolumn{5}{|l|}{ Ethnicity } \\
\hline White & 17070 & 96.2 & 14712 & 96.4 \\
\hline Minority ethnic group & 294 & 1.7 & 245 & 1.6 \\
\hline Unknown & 389 & 2.2 & 297 & 1.9 \\
\hline \multicolumn{5}{|l|}{ IMD category } \\
\hline 5 Most deprived & 1947 & 11.0 & 1606 & 10.5 \\
\hline 4 & 2935 & 16.5 & 2441 & 16.0 \\
\hline 3 & 3919 & 22.1 & 3335 & 21.9 \\
\hline 2 & 4419 & 24.9 & 3844 & 25.2 \\
\hline 1 Least deprived & 4533 & 25.5 & 4028 & 26.4 \\
\hline \multicolumn{5}{|l|}{ Physical activity (PA) } \\
\hline \multicolumn{5}{|l|}{ Received PA advice } \\
\hline Yes & 5038 & 28.4 & 4734 & 31 \\
\hline No & 11489 & 64.7 & 10520 & 69 \\
\hline Missing & 1226 & 6.9 & - & - \\
\hline \multicolumn{5}{|l|}{ Activity levels } \\
\hline None & 5803 & 32.7 & 5080 & 33.3 \\
\hline Some & 7547 & 42.5 & 6877 & 45.1 \\
\hline Meeting guidelines & 3626 & 20.4 & 3297 & 21.6 \\
\hline Missing & 777 & 4.4 & - & - \\
\hline \multicolumn{5}{|c|}{ Treatment and health variables } \\
\hline \multicolumn{5}{|l|}{ Treatment response } \\
\hline In remission & 13804 & 77.8 & 12026 & 78.8 \\
\hline Treated but still present & 857 & 4.8 & 741 & 4.9 \\
\hline Has not been treated & 159 & 0.9 & 123 & 0.8 \\
\hline Has come back & 437 & 2.5 & 388 & 2.5 \\
\hline Not certain & 1618 & 9.1 & 1341 & 8.8 \\
\hline Missing & 878 & 4.9 & 635 & 4.2 \\
\hline \multicolumn{5}{|l|}{ Time since treatment } \\
\hline Still having & 349 & 2.0 & 289 & 1.9 \\
\hline$<3$ months & 173 & 1.0 & 139 & 0.9 \\
\hline $3-12$ months & 2128 & 12.0 & 1799 & 11.8 \\
\hline $1-5$ years & 14501 & 81.7 & 12598 & 82.6 \\
\hline$>5$ years & 151 & 0.9 & 117 & 0.8 \\
\hline Do not know & 48 & 0.3 & 32 & 0.2 \\
\hline Missing & 403 & 2.3 & 280 & 1.8 \\
\hline \multicolumn{5}{|l|}{ Long-term condition } \\
\hline Yes & 8225 & 46.3 & 7160 & 46.9 \\
\hline No & 6733 & 37.9 & 5995 & 39.3 \\
\hline Do not know & 552 & 3.1 & 444 & 2.9 \\
\hline Missing & 2243 & 12.6 & 1655 & 10.8 \\
\hline
\end{tabular}

which found a clear benefit from clinician advice over usual care in the short term. ${ }^{16}$ Our results also concur with an earlier survey which found that only $28 \%$ of cancer survivors (predominantly breast and prostate) reported that the oncologist had initiated any discussion around PA, but that this discussion was associated with higher activity levels during treatment. ${ }^{7}$ Our results strengthen the case for clinicians to recommend PA to 
Table 2 Associations between being given physical activity (PA) advice, demographic factors, treatment and activity levels 2-3 years later in 15254 patients with colorectal cancer

\title{
PA advice
}

given $\mathbf{n}(\%)$

\section{Model 1 (unadjusted)}

OR $(95 \% \mathrm{Cl})$

\begin{abstract}
Total
$(n=15254)$

Sex
\end{abstract}

Reference category No PA advice

Female $(n=6091)$

Male $(n=9163)$

Age

$>85(n=777)$

$75-84(\mathrm{n}=3797)$

65-74 $(\mathrm{n}=5680)$

55-64 ( $\mathrm{n}=3677)$

IMD

$5(n=1606)$

$4(n=2441)$

$3(n=3335)$

$2(n=3844)$

$1(n=4028)$

Ethnicity

White $(n=14712)$

All other $(n=542)$

Time since treatment

Still having $(\mathrm{n}=289)$

$<1$ year $(n=1938)$

$\geq 1$ year $(n=12715)$

Unknown $(n=312)$

Treatment response

All other $(n=3228)$

In remission $(n=12$ 026)

Long-term condition

No $(n=5995)$

Unknown $(n=2099)$

Yes $(n=7160)$

*** $\mathrm{p}<0.001 ;{ }^{* *} \mathrm{p} \leq 0.01$

IMD, index of multiple deprivation; 5 , most deprived, 1 , least deprived model 1 is a simple binary logistic regression with having received physical activity (PA) advice (Y/N) as the dependent factor. Model 2 is a multivariable binary logistic regression model adjusting for all sociodemographic and treatment factors.

'All other' treatment factors (been treated but still present/has not been treated/has come back/not certain).

their patients with cancer. In the 'advice' group, the proportion of participants doing at least some activity was $10 \%$ higher than in the 'no advice' group, and those meeting the PA guidelines 5\% higher. This difference is potentially of real practical significance. ${ }^{14}$

Less than a third $(31 \%)$ of our large sample of CRC survivors recalled having received PA advice. Women, older patients and those from lower SES backgrounds were less likely to recall having been given advice. Older patients were also less likely to have received advice in a Canadian survey, which the authors speculated could be due to them being less likely to initiate discussions about $\mathrm{PA}^{7}$ although nearly all patients expressed a wish for their oncologist to initiate the discussion. ${ }^{7}$ Clinicians may want to consider whether these populations need more targeted advice to help make access to important lifestyle advice more equitable.
Giving PA advice may not always be easy for healthcare professionals. A recent qualitative study with cancer specialists identified lack of appropriate support as a barrier to discussing lifestyle with patients with cancer. ${ }^{23}$ This may be particularly applicable when discussing PA with vulnerable groups, such as older patients and those from lower SES groups. The same study also found that some specialists did not believe that lifestyle change would influence cancer risk and cited this as a reason for not discussing it. In a recent survey completed by 323 CRC clinicians in Scotland, only half (52\%) reported being familiar with the lifestyle advice for patients with CRC and many felt they lacked the skills, confidence and knowledge to discuss it. ${ }^{24}$ In line with this, a survey of 274 oncology nurses found being 'unsure what to recommend' was strongly related to whether they gave advice or not. ${ }^{25}$ Insufficient time 
Table 3 Associations between recall of being given physical activity advice, demographic factors and activity levels in 15254 patients with colorectal cancer

\begin{tabular}{|c|c|c|c|c|}
\hline $\begin{array}{l}\text { PA level } \\
\text { (reference 'None') }\end{array}$ & $\begin{array}{l}\text { Model } 1 \text { (unadjusted) } \\
\text { OR }(95 \% \mathrm{CI}) \\
\text { Some PA }\end{array}$ & $\begin{array}{l}\text { Model } 1 \text { (unadjusted) } \\
\text { OR ( } 95 \% \mathrm{Cl}) \\
\text { Meeting guidelines }\end{array}$ & $\begin{array}{l}\text { Model } 2 \text { (adjusted) } \\
\text { OR }(95 \% \mathrm{Cl}) \\
\text { Some PA }\end{array}$ & $\begin{array}{l}\text { Model } 2 \text { (adjusted) } \\
\text { OR }(95 \% \mathrm{Cl}) \\
\text { Meeting guidelines }\end{array}$ \\
\hline \multicolumn{5}{|l|}{ PA advice given } \\
\hline No $(n=10520)$ & 1 & 1 & 1 & 1 \\
\hline Yes $(n=4734)$ & $1.88(1.74 \text { to } 2.05)^{\star \star \star}$ & $1.90(1.75 \text { to } 2.09)^{\star \star \star}$ & $1.74(1.60 \text { to } 1.90)^{\star \star \star}$ & $1.70(1.54 \text { to } 1.88)^{\star \star \star}$ \\
\hline \multicolumn{5}{|l|}{ Sex } \\
\hline Female $(n=6091)$ & 1 & 1 & 1 & 1 \\
\hline Male $(n=9163)$ & $1.11(1.03 \text { to } 1.20)^{\star \star \star}$ & $1.75(1.60 \text { to } 1.92)^{\star \star \star}$ & $1.04(0.96$ to 1.12$)$ & $1.63(1.49 \text { to } 1.80)^{\star \star \star}$ \\
\hline \multicolumn{5}{|l|}{ Age } \\
\hline$\geq 85(n=777)$ & 1 & 1 & 1 & 1 \\
\hline$\overline{7} 5-84(n=3797)$ & $2.21(1.85 \text { to } 2.66)^{\star \star \star}$ & $2.20(1.76 \text { to } 2.76)^{\star \star \star}$ & $2.21(1.84 \text { to } 2.65)^{\star \star \star}$ & $2.15(1.71 \text { to } 2.70)^{\star \star \star}$ \\
\hline $65-74(n=5680)$ & $4.11(3.44 \text { to } 4.91)^{\star \star \star}$ & $3.62(2.90 \text { to } 4.52)^{\star \star \star}$ & $4.05(3.38 \text { to } 4.85)^{\star \star \star}$ & $3.43(2.74 \text { to } 4.29)^{\star \star \star}$ \\
\hline $55-64(n=3677)$ & $4.64(3.86 \text { to } 5.57)^{\star \star \star}$ & $3.64(2.89 \text { to } 4.78)^{\star \star * *}$ & $4.48(3.72 \text { to } 5.40)^{\star \star \star}$ & $3.42(2.74 \text { to } 4.29)^{\star \star *}$ \\
\hline$<55(n=1323)$ & $4.30(3.49 \text { to } 5.30)^{\star \star \star}$ & $3.06(2.34 \text { to } 3.98)^{\star \star *}$ & $4.22(3.41 \text { to } 5.21)^{\star \star \star}$ & $3.00(2.31 \text { to } 3.92)^{\star \star \star}$ \\
\hline \multicolumn{5}{|l|}{ IMD } \\
\hline $5(n=1606)$ & 1 & 1 & 1 & 1 \\
\hline $4(n=2441)$ & $1.17(1.01$ to 1.34$)$ & 1.17 (0.99 to 1.39$)$ & $1.22(1.06 \text { to } 1.41)^{\star \star}$ & $1.23(1.04$ to 1.47$)$ \\
\hline $3(n=3335)$ & $1.35(1.18 \text { to } 1.54)^{\star \star \star}$ & $1.24(1.05$ to 1.45$)$ & $1.41(1.23 \text { to } 1.61)^{\star \star \star}$ & $1.30(1.10 \text { to } 1.53)^{\star \star}$ \\
\hline $2(n=3844)$ & $1.68(1.47 \text { to } 1.92)^{\star \star \star}$ & $1.46(1.25 \text { to } 1.72)^{\star \star \star}$ & $1.75(1.53 \text { to } 2.00)^{\star \star \star}$ & $1.53(1.30 \text { to } 1.79)^{\star \star \star}$ \\
\hline $1(n=4028)$ & $1.85(1.62 \text { to } 2.11)^{\star \star \star}$ & $1.52(1.30 \text { to } 1.79)^{\star \star \star}$ & $1.95(1.71 \text { to } 2.24)^{\star \star \star}$ & $1.61(1.37 \text { to } 1.89)^{\star \star \star}$ \\
\hline \multicolumn{5}{|l|}{ Ethnicity } \\
\hline White $(n=14712)$ & 1 & 1 & 1 & 1 \\
\hline All other $(n=542)$ & $1.01(0.83$ to 1.23$)$ & 1.04 (0.82 to 1.32$)$ & $1.00(0.82$ to 1.23$)$ & $1.02(0.81$ to 1.30$)$ \\
\hline
\end{tabular}

during the consultation was identified as a barrier in another study, along with unclear recommendations. ${ }^{8}$ These observations indicate a need to address the gaps

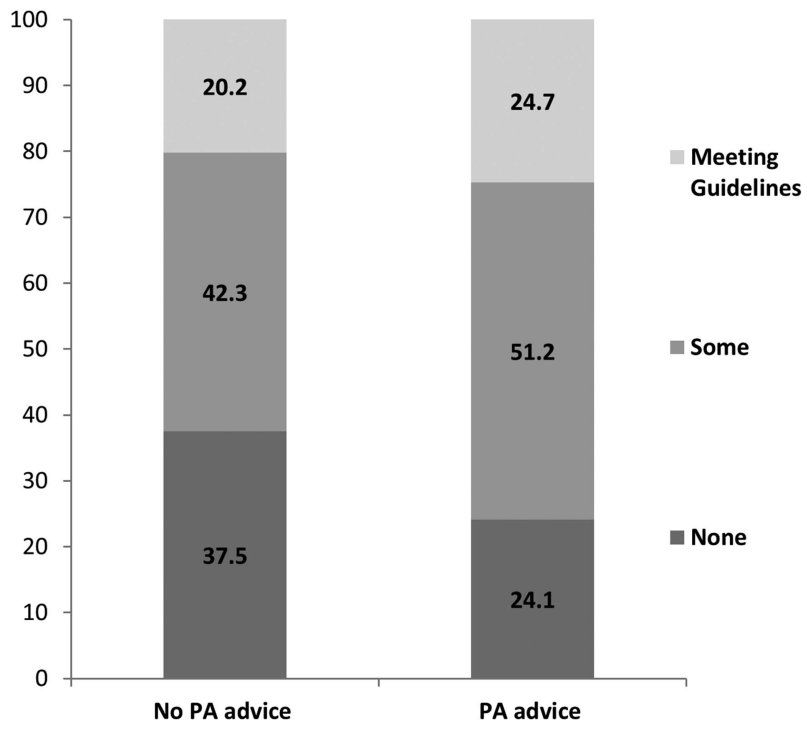

Figure 1 Proportions of patients doing at least some activity, or meeting the guidelines by advice. Values are from $n=15254$ colorectal cancer patients who reported the number of days brisk physical activity (PA) was carried out in the past week as none, some (1-4 days) or meeting guidelines (5-7 days). $\chi^{2}$ value for difference s262.822; $p<0.001$. in knowledge and skills while keeping in mind the time constraints in consultations. Finally, the evidence that PA reduces risk of recurrence and cancer-specific mortality in CRC currently comes from observational cohorts $;^{1}$ results of an RCT examining PA effects on survival of CRC (CHALLENGE) ${ }^{26}$ are not yet available, so clinicians may not yet be convinced to recommend PA for survival outcomes. However, in light of strong evidence for a number of other important outcomes, such as reductions in cancer-related fatigue and improved quality of life, ${ }^{3}$ it is important for clinicians to be advising their patients with CRC to be physically active.

This study had limitations. Data were self-reported using single item measures, so PA may have been underestimated or over-estimated. Additionally, no information was gathered on who gave the advice and when in the care pathway. This study was based on secondary analyses of existing large-scale PROMS data and provides an important 'first step'. Future large-scale surveys in cancer survivors should use validated measures of PA and collect detailed information on the context of the delivery of the PA advice. Information on receiving PA advice depended on patient recall and therefore, could also be under-estimated or over-estimated. Consistency with findings from other studies, both from the patient and the health professional perspective, is 
Table 4 Associations between being given physical activity (PA) advice, treatment and activity levels 2-3 years later in 15254 patients with colorectal cancer

\begin{tabular}{|c|c|c|c|c|}
\hline PA level (reference 'none') & $\begin{array}{l}\text { Model } 1 \text { (unadjusted) } \\
\text { OR }(95 \% \mathrm{Cl}) \\
\text { Some PA }\end{array}$ & $\begin{array}{l}\text { Model } 1 \text { (unadjusted) } \\
\text { OR }(95 \% \mathrm{CI}) \\
\text { Meeting guidelines }\end{array}$ & $\begin{array}{l}\text { Model } 2 \text { (adjusted) } \\
\text { OR }(95 \% \mathrm{Cl}) \\
\text { Some PA }\end{array}$ & $\begin{array}{l}\text { Model } 2 \text { (adjusted) } \\
\text { OR ( } 95 \% \mathrm{Cl}) \\
\text { Meeting guidelines } \\
\end{array}$ \\
\hline \multicolumn{5}{|l|}{ PA advice given } \\
\hline No $(n=10520)$ & 1 & 1 & 1 & 1 \\
\hline Yes $(n=4734)$ & $1.88(1.74 \text { to } 2.05)^{\star \star *}$ & $1.90(1.75 \text { to } 2.09)^{\star \star \star}$ & $1.76(1.61 \text { to } 1.91)^{\star * *}$ & $1.79(1.56 \text { to } 1.92)^{\star \star *}$ \\
\hline \multicolumn{5}{|l|}{ Time since treatment } \\
\hline Still having $(\mathrm{n}=289)$ & 1 & 1 & 1 & 1 \\
\hline$<1$ year $(n=1938)$ & $1.34(1.02$ to 1.76$)$ & $1.26(0.89$ to 1.77$)$ & $1.06(0.79$ to 1.41$)$ & 0.96 (0.67 to 1.37$)$ \\
\hline$\geq 1$ year $(n=12715)$ & $1.59(1.22 \text { to } 2.05)^{\star * *}$ & $1.57(1.14 \text { to } 2.17)^{\star \star \star}$ & $1.22(0.93$ to 1.60$)$ & $1.14(0.82$ to 1.60$)$ \\
\hline Unknown $(n=312)$ & 0.78 (0.50 to 1.22$)$ & 0.78 (0.49 to 1.22$)$ & $1.07(0.73$ to 1.54$)$ & $1.03(0.64$ to 1.63$)$ \\
\hline \multicolumn{5}{|l|}{ Treatment response } \\
\hline All other $(n=3228)$ & 1 & 1 & 1 & 1 \\
\hline In remission $(\mathrm{n}=12$ 026) & $1.89(1.73 \text { to } 2.06)^{\star \star *}$ & $2.15(1.92 \text { to } 2.40)^{\star \star *}$ & $1.65(1.50 \text { to } 1.81)^{\star \star *}$ & $1.90(1.69 \text { to } 2.13)^{\star \star \star}$ \\
\hline \multicolumn{5}{|l|}{ Long-term condition } \\
\hline Yes $(n=7160)$ & 1 & 1 & 1 & 1 \\
\hline Unknown (n=2099) & $1.22(1.10 \text { to } 1.37)^{\star \star \star}$ & $1.42(1.24 \text { to } 1.62)^{\star \star \star}$ & $1.28(13.14 \text { to } 1.43)^{\star \star \star}$ & $1.49(1.30 \text { to } 1.71)^{\star *}$ \\
\hline No $(n=5995)$ & $1.88(1.74 \text { to } 2.04)^{\star \star \star}$ & $2.24(2.03 \text { to } 2.47)^{\star \star \star}$ & $1.73(1.59 \text { to } 1389)^{\star \star \star}$ & $2.17(1.97 \text { to } 2.40)^{\star \star \star}$ \\
\hline
\end{tabular}

reassuring. ${ }^{7-11}$ It is also important to note that recall of advice is an important outcome in itself in this context. ${ }^{16}$

The possibility that those recalling PA advice were already more aware of the importance of PA or had higher pretreatment levels cannot be ruled out, and longitudinal studies are warranted. However, this could also suggest the need for research on how to make important messages about PA more salient to those who are less active and less engaged. One RCT in the field suggested that clinician's brief exercise advice increased subsequent activity levels of breast cancer survivors ${ }^{16}$ and though this is very promising, trials in other cancers and with long-term follow-ups are required. The use of patient-reported disease and treatment variables should also be viewed with caution. Additionally, the sample were predominantly white, older and in remission, which means that the findings cannot be generalised to other populations. A further limitation is the lack of data on cancer staging, because patients with more advanced disease may be less likely to have been given advice or to be doing any PA. In clinician surveys, disease stage has not been raised as a major concern; rather the lack of knowledge and time are cited as key barriers. $^{25}$

\section{CONCLUSION}

Recalling being given PA advice after a diagnosis of CRC was associated with higher levels of PA. However, less than a third of patients recalled receiving advice. Future research should examine the context in which advice is given. However, encouraging clinicians working with
CRC patients to give brief PA advice is warranted and may help improve outcomes for CRC survivors.

Acknowledgements The authors are extremely grateful to the patients who completed the PROMS questionnaires and to the National Cancer Registration Service in Public Health England for providing the data.

Contributors AF, KW, RB and JW contributed to the conception and design of the work. AF carried out the analyses and drafted the paper. KW, RB and JW contributed to interpretation of the analyses and revised the work critically for important intellectual content. All authors approved the final version of submission.

Funding $\mathrm{AF}, \mathrm{RB}$ and JW were funded by Cancer Research UK (grant number C1418/A14133). KW was funded by a Cancer Research UK PhD studentship.

Competing interests None declared.

Provenance and peer review Not commissioned; externally peer reviewed.

Data sharing statement No additional data are available.

Open Access This is an Open Access article distributed in accordance with the terms of the Creative Commons Attribution (CC BY 4.0) license, which permits others to distribute, remix, adapt and build upon this work, for commercial use, provided the original work is properly cited. See: http:// creativecommons.org/licenses/by/4.0/

\section{REFERENCES}

1. Je Y, Jeon JY, Giovannucci EL, et al. Associations between physical activity and mortality in colorectal cancer: a meta-analysis of prospective cohort studies. Int J Cancer 2013;133: 1905-13.

2. Campbell PT, Patel AV, Newton CC, et al. Associations of recreational physical activity and leisure time spent sitting with colorectal cancer survival. J Clin Oncol 2013;31:876-85.

3. Peddle CJ, Au HS, Courneya KS. Associations between exercise, quality of life, and fatigue in colorectal cancer survivors. Dis Colon Rectum 2008;51:1242-8.

4. Hawkes A, Lynch BM, Owen N, et al. Health behaviours of Australian colorectal cancer survivors compared to non-cancer population controls. J Support Care Cancer 2008;16:1097-104. 
5. Williams K, Steptoe A, Wardle J. Is a cancer diagnosis a trigger for health behaviour change? Findings from a prospective, populationbased study. Br J Cancer 2013;108:2407-12.

6. O'Leary KA, Estabrooks CA, Olson K, et al. Information acquisition for woman facing surgical treatment for breast cancer: influencing factors and selected outcomes. Patient Educ Couns 2007;69:5-19.

7. Jones LW, Courneya KS. Exercise discussions during cancer treatment consultations. Cancer Pract 2002;10:66-74.

8. Karvinen $\mathrm{KH}$, DuBose KD, Carney B, et al. Promotion of physical activity amongst oncologists in the United States. J Support Oncol 2010;8:35-41.

9. Daley AJ, Bowden SJ, Rea DW, et al. What advice are oncologists and surgeons in the United Kingdom giving to breast cancer patients about physical activity? Int J Behav Nutr Physical Activity 2008;5:46.

10. MacMillan Move More, Physical activity the underrated wonder drug 2011. http://www.macmillan.org.uk/Documents/AboutUs/Newsroom/ Physicalactivityreport.pdf (accessed Jun 2014)

11. Stull VB, Snyder DC, Demark-Wahnefried W. Lifestyle interventions in cancer survivors: designing programs that meet the needs of this vulnerable and growing population. J Nutr 2013:243S-8.

12. Barnes MA, Schoenborn CA. Trends in adults recieving a recommendation for exercise or other physical activity from a physician or other health professional: NCHS data brief no 86. Hyattsville, MD: National Centre for Health Statistics, 2012.

13. Calfas KJ, Long BJ, Sallis JF, et al. A controlled trial of physician counseling to promote the adoption of physical activity. Prev Med 1996;25:225-33.

14. Hillsdon M, Foster C, Cavill N, et al. The effectiveness of public health interventions of increasing physical activity among adults: a review of reviews. NHS Health Development Agency, 2005. http://www.nice.org.uk/nicemedia/documents/physical_activity_ adults_ebsummary.pdf (accessed Jun 2014).

15. Segar ML, Katch VL, Roth RS, et al. The effect of aerobic exercise on self-esteem and depressive and anxiety symptoms among breast cancer survivors. Oncol Nurs Forum 1998;25:107-13.

16. Jones LW, Courneya KS, Fairey AS, et al. Effects of an oncologist's recommendation to exercise on self-reported behaviour in newly diagnosed breast cancer survivors: a single-blind randomized controlled trial. Ann Behav Med 2004;28:105-13.

17. Glaser A, Fraser LK, Corner J, et al. Patient reported outcomes of cancer survivors in England 1-5 years after diagnosis: a crosssectional survey. BMJ Open 2013;3:e002371.

18. Hadi M, Gibbons E, Fitzpatrick R. A structured review of Patient Reported Outcome Measures (PROMS) for colorectal cancer Report to the Department of Health, 2010. http://phi.uhce.ox.ac.uk/ pdf/CancerReviews/PROMs_Oxford_Colorectal\%20Cancer_012011. pdf/ (accessed Jun 2014).

19. Department of Health. Start active, stay active: a report of physical activity from the four home countries. Chief Medical Officers, 2011. file://ad.ucl.ac.uk/slms/home1/rmjdafi/Downloads/C-Documents\% 20 and $\% 20$ Settings-sharona-Desktop-Start\%20Active, $\% 20$ Stay $\%$ 20Active\%20-\%20UK\%20Guidelines\%20for\%20PA.pdf (accessed Jun 2014).

20. Schmitz KH, Courneya KS, Matthews C, et al. American College of Sports Medicine round table on exercise guidelines for cancer survivors. Med Sci Sports Excer 2010;42:1409-26.

21. Department for Communities and Local Government: English Indices of Multiple Deprivation. 2010. https://www.gov.uk/government/ statistics/english-indices-of-deprivation-2010 (accessed Feb 2015).

22. Downing A, Morris EJ, Richards $M$, et al. Health-related quality after colorectal cancer in England: a patient-reported outcomes study of individuals 12 to 36 months after diagnosis. J Clin Oncol 2015;33:616-24.

23. Miles A, Simon A, Wardle J. Answering patient questions about the role lifestyle factors play in cancer onsent and reccurence: what do health care professionals say? J Health Psychol 2010;15:291-8.

24. Anderson AS, Caswell S, Wells M, et al. Obesity and lifestyle advice in colorectal cancer survivors-how well are clinicians prepared? Colorectal Dis 2013;15:949-57.

25. Karvinen KH, McGourty S, Parent T, et al. Physical activity promotion among oncology nurses. Cancer Nurs 2012;35:E41-8.

26. Courneya KS, Booth CM, Gill S, et al. The Colon Health and Life-Long Exercise Change (CHALLENGE) trial: a randomized trial of the National Cancer Institute of Canada Clinical Trials Group. Cur Oncol 2008;15:279-85. 